\title{
Хроматографическое разделение продуктов взаимодействия 1,1-диметилгидразина с изотиоцианатами
}

\author{
Ульянов А.В., Полунина И.А., Полунин К.Е., Буряк А.К. \\ ФГБУН Институт физической химии и электрохимии им. А.Н. Фрумкина РАН, Москва
}

Поступила в редакцию 26.01.2019 г.

DOI: https://doi.org/10.17308/sorpchrom.2019.19/730

Проведены теоретические и экспериментальные исследования возможности хроматографического разделения смеси реагентов и продуктов взаимодействия 1,1-диметилгидразина с изотиоцианатами. Методом газовой хроматографии с масс-спектрометрической детекцией эффективно разделены смеси этил- и аллилтиосемикарбазидов с реагентами на полидиметилсилоксановой неподвижной фазе. Получена удовлетворительная корреляция между экспериментальными и теоретически рассчитанными характеристиками удерживания тиосемикарбазидов и изотиоцианатов на неполярной неподвижной фазе.

Ключевые слова: 1,1-диметилгидразин, изотиоцианаты, тиосемикарбазиды, газовая хроматография, термодинамические характеристики адсорбции

\section{Chromatographic separation of reaction products of 1,1-dimethylhydrazine and isothiocyanates}

\author{
Ulyanov A.V., Polunina I.A., Polunin K.E., Buryak A.K. \\ A.N. Frumkin Institute of Physical Chemistry and Electrochemistry, RAS, Moscow
}

1,1-Dimethylhydrazine is a toxic component of a widely used rocket fuel. Chromatographic determination of polar 1,1-dimethylhydrazine in aqueous solutions is carried out as the analysis of its non-polar derivatives usually. The 1,1-dimethylthiosemicarbazides were synthesized as the reaction products of 1,1dimethylhydrazine and ethyl-, allyl-, and phenyl- isothiocyanates. The purpose of this work was to investigate the possibility of the chromatographic separation of the reagents and the reaction products as well as to create the grounds of the quantity analysis of 1,1-dimethylhydrazine in aqueous solutions as its S,N-derivatives. Theoretical and experimental studies of the chromatographic behavior and adsorption characteristics of different thiosemicarbazides were carried out. It was shown that allyl- and ethyl-isothiocyanates, and corresponding derivatives of 1,1-dimethylhydrazine (1,1-dimethylthiosemicarbazides) can be separated effectively by gas chromatography-mass spectrometry technique using a capillary column with polydimetylsiloxane. Mass-spectra of ethyland allyl- thiosemicarbazides were obtained and investigated. Retention characteristics of isothiocyanates and thiosemicarbazides were calculated by two different methods. The molecular statistical calculations of their adsorption characteristics on the ideal carbon surface were performed as well as their retention characteristics were calculated using the increments of the functional groups of isothiocyanates and thiosemicarbazides. The simplified models of molecules with rigid and non-rigid bond lengths were used. The different approaches to taking into account of internal rotation of the molecule were used A satisfactory correlation has been obtained between the experimental and theoretically calculated retention characteristics of thiosemicarbazides and isothiocyanates on the non-polar stationary phase. The derivative of 1,1-dimethylhydrazine with phenylisothiocyanate is too thermally unstable to be analyzed by gas chromatography. The recommendations on gas chromatographic analysis of such mixtures are given.

Keywords: 1,1-dimethylhydrazine, isothiocyanates, thiosemicarbazides, gas chromatography, thermodynamic adsorption characteristics 


\section{Введение}

1,1-Диметилгидразин (ДГ) - чрезвычайно токсичное физиологически активное соединение, которое характеризуется крайней неустойчивостью на воздухе и быстрой трансформацией в многочисленные более или менее токсичные соединения [1]. В настоящее время задача идентификации ДГ, а также продуктов его трансформации в объектах окружающей среды является весьма актуальной, так как существующие физико-химические методы анализа гидразинов имеют ряд недостатков низкую чувствительность и селективность, необходимость долгой и трудоемкой пробоподготовки $[2,3]$. Высокая полярность гидразинов, их производных и продуктов трансформации, а так же чрезвычайно высокая реакционная способность этих соединений осложняют анализ этих токсичных соединений хроматографическими методами. С целью понижения предела обнаружения примесных концентраций ДГ в объектах окружающей среды было предложено использовать его дериваты для предили послеколоночной дериватизации этого суперэкотоксиканта. В качестве дериватизатора для ДГ чаще всего применяют ароматические альдегиды, ацетон, пентафторбензоилхлорид и другие соединения [4]. В [5, 6] предложено использовать соединения с изотиоцианатной группой. Преимуществом дериватизации гидразинов с помощью изотиоцианатов, по сравнению с другими типами дериватизирующих реагентов, является отсутствие элиминирования воды или галогеноводородов, осложняющих последующее проведение хроматографического анализа.

Наличие в составе тиосемикарбазидов функциональных групп небольшой полярности обусловливает необходимость использования в хроматографической системе неполярных сорбентов для уменьшения энергии взаимодействия на границе раздела фаз. В газовой хроматографии разделение смесей обусловлено селективным взаимодействием между веществами и неподвижной фазой. Хорошую эффективность разделения показывают капиллярные колонки с нанесенной полидиметилсилоксановой неподвижной фазой. Разделение проводят, как правило, при температуре выше температуры кипения используемых соединений.

Изучение физикохимии адсорбции производных ДГ на поверхности углеродных сорбентов имеет большое значение как для аналитического разделения этих веществ на углеродных колонках, так и для их сорбции из различных растворов и объектов окружающей среды. Теоретическое изучение физикохимии адсорбции данных аналитов на поверхности углеродного хроматографического сорбента может быть выполнено с использованием молекулярно-статистического метода.

Целью настоящего исследования является экспериментальная и теоретическая оценка возможности разделения смеси различных тиосемикарбазидов (дериватов ДГ) и исходных реагентов-дериватизаторов (изотиоционатов) методом газовой хроматографии с масс-спектрометрической детекцией.

\section{Эксперимент}

В работе использовали 1,1-диметилгидразин (ГОСТ В 17803-72, Нефтеоргсинтез, РФ), который был дополнительно перегнан над гидроксидом натрия перед использованием. Чистые дериваты алкилгидразинов (тиосемикарбазиды) были получены по методике [5] путем добавления свежеперегнанного ДГ к раствору изотиоцианата в дихлорметане при $20^{\circ} \mathrm{C}$ без доступа воздуха. Использовались реагенты 99\% чистоты от фирмы Aldrich (США): этилизотиоцианат EtNCS, аллилизотиоцианат AllNCS, фенилизотиоцианат PhNCS, дихлорметан. 
Анализ реакционных смесей проводили на хромато-масс-спектрометре JEOL JMS-D300 (JEOL, Япония) с хроматографом HP-5890 (Hewlett-Packard, CША). Для хроматографического разделения применяли кварцевую капиллярную колонку размером 30 м×0.35 мм с неподвижной фазой DB-5 (J\&W Scientific Inc., CША), содержащей 95\% диметилполисилоксана и 5\% дифенилполисилоксана. Режим хроматографического разделения: температура инжектора повышалась со скоростью $5^{\circ} \mathrm{C} /$ мин до $300^{\circ} \mathrm{C}$ с последующим изотермическим режимом в течение 15 мин, скорость газа-носителя гелия - $5 \mathrm{~cm}^{3} /$ мин, деление потока $1: 10$. В инжектор хроматографа вводили 1 мкл реакционной смеси. Хроматограммы регистрировали по полному ионному току при энергии ионизирующих электронов 70 эВ, диапазон массовых чисел от 15 до $450 \mathrm{~m} / \mathrm{z}$. Идентификацию осуществляли с помощью программы библиотечного поиска и на основании расшифровки масс-спектров с использованием основных закономерностей фрагментации органических соединений при ионизации электронами [7].

Молекулярно-статистический расчет термодинамических характеристик адсорбции на однородной идеальной поверхности углеродного сорбента проводили, опираясь на полуэмпирическую молекулярно-статистическую теорию адсорбции, разработанную А.В. Киселевым и Д.П. Пошкусом [8], посредством вычисления конфигурационных интегралов в адсорбированном и свободном состоянии. Потенциальная функция $\Phi$ межмолекулярного взаимодействия молекул адсорбата с адсорбентом представлялась в виде суммы атом-атомных потенциалов межмолекулярного взаимодействия атомов $\mathrm{C}, \mathrm{H}, \mathrm{N}$ и $\mathrm{S}$ в молекулах сорбатов с атомами сорбента. Предполагалось, что сорбент имеет идеальную плоскую поверхность, равномерно заполненную незаряженными атомами углерода. В первом варианте молекулярностатистического расчета молекула адсорбата рассматривается как жесткая структура, имеющая фиксированную геометрию. Во втором варианте использовали приближение для нежестких молекул, т.е. молекул, способных изменять конформацию при взаимодействии с плоской поверхностью графитоподобного сорбента. Для расчета параметров атом-атомных потенциалов взаимодействия адсорбат-адсорбент в первом случае использовали потенциал в форме Бакингема-Корнера $[8,9]$

$$
\varphi=-C_{1} r^{-6}-C_{2} r^{-8}+B \cdot \exp (-q r),
$$

где $C_{1}$ и $C_{2}$ - параметры сил диполь-дипольного и диполь-квадрупольного дисперсионного притяжения, $B$ и $q$ - параметры сил отталкивания, $r$ - расстояние между взаимодействующими силовыми центрами (атомами молекулы адсорбата и решетки адсорбента).

Во втором случае использовали потенциал в форме Леннард-Джонса [8, 10], аналитически проинтегрированного по бесконечной двумерной поверхности:

$$
\Phi=\vartheta \pi \sum_{i=0}^{i=N} \frac{1}{2 d^{4}} A_{i} \xi\left(\frac{z_{i}}{d}, 4\right)-\frac{1}{2 d^{4}} B_{i} \xi\left(\frac{z_{i}}{d}, 10\right),
$$

где $d$ - постоянная, характеризующая расстояние между слоями графита, $N$ - количество атомов в молекуле, $\vartheta$ - плотность расположения атомов углерода на поверхности, $A_{i}, B_{i}$ - параметры взаимодействия для $i$-ого атома, $z_{i}$ - расстояние $i$-ого атома от плоскости графита.

Физико-химические и геометрические параметры рассматриваемых молекул получены из справочных и литературных данных [8-11]. Перебор конформаций выполнялся посредством алгоритма Метрополиса; произвольные шаги включали в себя поворот молекулы вокруг произвольной связи, перемещение произвольного атома (до $0.1 \AA$ ) и изменение длины произвольной связи (до $0.1 \AA$ ) с вероятностями 0.25 , 0.5 и 0.25 , соответственно; вращению подвергались все одинарные связи, кроме связей $\mathrm{N}-\mathrm{H}$ и $\mathrm{C}-\mathrm{H}[9,10]$. 
Для теоретической оценки адсорбции изотиоцианатов и дериватов ДГ на полидиметилсилоксане применение молекулярно-статистического метода невозможно, поэтому использовался метод расчета индексов удерживания $I$ в соответствии с инкрементами имеющихся в молекулах функциональных групп $[12,13]$. Расчет выполнялся по формуле: $I=h+\sum_{i} f_{i} g_{i}$, где $f_{i}$ - количество функциональных групп $i$-ого вида, $g_{i}-$ инкремент, соответствующий данной функциональной группе, $h$ - эмпирически подобранная константа.

\section{Обсуждение результатов}

На рис. 1 приведена структурная формула 4-R-1,1-диметилтиосемикарбазидов - продуктов взаимодействия ДГ с избытком изотиоцианатов RNCS, где R - этильный Et, аллильный All или фенильный Рh углеводородные радикалы. Реакция дериватизации протекает до конца за 1 ч, а ее продукты относительно стабильны [5].<smiles>[R]NC(=S)NN(C)C</smiles>

Рис. 1. Структурная формула 4-R-1,1-диметилтиосемикарбазидов

Поскольку алкилтиосемикарбазиды сравнительно малодоступны и являются сложным объектом для хроматографического анализа, то предварительная оценка характеристик удерживания этих соединений на различных хроматографических колонках представляет значительный интерес. К теоретическим методам оценки адсорбции относятся различные эмпирические формулы и методы машинного обучения, с одной стороны, и молекулярно-статистический метод моделирования адсорбции, с другой стороны. Молекулярно-статистический метод опирается на полуэмпирическую молекулярно-статистическую теорию адсорбции и атом-атомное приближение для взаимодействия адсорбат-адсорбент [7] и позволяет выполнить непосредственное моделирование адсорбционного процесса.

В табл. 1 приведены результаты расчетов термодинамических характеристик адсорбции 4-этил-1,1-диметилтиосемикарбазида (I), 4-аллил-1,1-диметилтиосемикарбазида (II) и 4-фенил-1,1-диметилтиосемикарбазида (III) на поверхности модельного углеродного сорбента, обладающего однородной плоской поверхностью при температуре 298 К. Расчет параметров атом-атомного потенциала межмолекулярного взаимодействия был выполнен в двух вариантах: для жестких молекул адсорбата и нежестких молекул с учетом их внутреннего вращения.

Таблица 1. Термодинамические характеристики адсорбции 4-этил-1,1-диметилтиосемикарбазида (I), 4-аллил-1,1-диметилтиосемикарбазида (II) и 4-фенил-1,1диметилтиосемикарбазида (III) при 298 К на поверхности модельного углеродного сорбента, рассчитанные без учета внутреннего вращения (метод 1) и с учетом внутреннего вращения (метод 2)

\begin{tabular}{|c|c|c|c|c|c|c|}
\hline \multirow{2}{*}{ Вещество } & \multicolumn{3}{|c|}{ Метод расчета } & \multicolumn{3}{c|}{ Метод расчета 2 } \\
\cline { 2 - 7 } & $\begin{array}{c}-\Delta H^{\mathrm{o}}, \\
\text { кДж/моль }\end{array}$ & $\begin{array}{c}-\Delta S^{\mathrm{o}}, \\
\text { Дж моль)/К }\end{array}$ & $\begin{array}{c}-\Delta G^{\mathrm{o}}, \\
\text { кДж/моль }\end{array}$ & $\begin{array}{c}-\Delta H^{\mathrm{o}}, \\
\text { кДж/моль }\end{array}$ & $\begin{array}{c}-\Delta S^{\mathrm{o}}, \\
\text { Дж моль/К }\end{array}$ & $\begin{array}{c}-\Delta G^{\mathrm{o}}, \\
\text { кДж/моль }\end{array}$ \\
\hline I & 72.7 & 129.4 & 34.2 & 54.1 & 115.2 & 19.8 \\
\hline II & 78.9 & 131.2 & 39.8 & 57.7 & 117.9 & 22.6 \\
\hline III & 85.5 & 135.0 & 45.3 & 84.7 & 136.0 & 44.1 \\
\hline
\end{tabular}

Сравнение значений дифференциальных мольных энергий адсорбции Гиббса $\Delta G^{\mathrm{o}}$, энтальпии $\Delta H^{\mathrm{o}}$ и энтропии $\Delta S^{\mathrm{o}}$ для трех тиосемикарбазидов, приведенных в 
табл. 1, позволяет обнаружить, что увеличение термодинамических характеристик адсорбции наблюдается в ряду I-II-III. Поскольку эти соединения отличаются только природой углеводородного заместителя $R$, то адсорбционные характеристики тиосемикарбазидов увеличиваются с увеличением количества атомов углерода: $\mathrm{C}_{2} \mathrm{H}_{5}-\mathrm{C}_{3} \mathrm{H}_{5}-\mathrm{C}_{6} \mathrm{H}_{5}$. Соединение с этильным радикалом I адсорбируется слабее всех еще и благодаря особенностям его стереохимии: этильный радикал имеет пространственное строение ( $s p^{3}$-гибридизация атома углерода), тогда как фенильный и аллильный радикалы ( $s p^{2}$-гибридизация) лежат в одной плоскости. Предполагается, что плоские молекулы способны вплотную подходить к поверхности сорбента, сильнее с ней взаимодействовать и дольше удерживаться.

Приведенные в табл. 1 значения термодинамических параметров адсорбции, рассчитанные с учетом внутреннего вращения (метод 2), несколько меньше, чем соответствующие значения, полученные при расчетах по методу (1). Это отличие связано с особенностями программного обеспечения двух методов и не представляется существенным, т.к. данные характеристики используются лишь для качественного анализа возможности разделения тиосемикарбазидов. Для соединения III, содержащего фенильную группу, результаты расчетов по двум методам практически совпадают. Это свидетельствует о том, что вблизи плоской поверхности сорбента стабилизируются конформации с меньшим углом между бензольным кольцом и плоским фрагментом, образуемым атомом серы и двумя атомами азота, соединенными с одним и тем же атомом углерода. Равновесный угол в газовой фазе может существенно отличаться от угла вблизи поверхности, т.к. чем ближе расположение плоских фрагментов молекулы к копланарному, тем сильнее потенциальная энергия взаимодействия сорбат-сорбент.

В табл. 2 приведены расчеты индексов удерживания тиосемикарбазидов и исходных реагентов RNCS (этил-, аллил- и фенил- изотиоцианатов) на полидиметилсилоксане в соответствии с инкрементами функциональных групп. Расчет показывает, что в условиях газовой хроматографии достаточно легко разделить исходные реагенты и соответствующие им производные. Производное III, содержащее бензольное кольцо, также теоретически может быть легко отделено от двух других рассматриваемых соединений. Однако, согласно расчетам [13], его температура кипения $319^{\circ} \mathrm{C}$ выше температуры инжектора хроматографа. Небольшая разница между рассчитанными индексами удерживания для дериватов I и II с большой долей вероятности, приведет к перекрыванию их хроматографических пиков и сложности их полного разделения.

Таблица 2. Индексы удерживания $I_{r} 1,1$-диметилтиосемикарбазидов (I-III) и изотиоцианатов RNCS на полидиметилсилоксановой неподвижной фазе DB-5

\begin{tabular}{|c|c|c|c|c|c|}
\hline \multicolumn{6}{|c|}{ Вещество } \\
\hline I & II & III & EtNCS & AllNCS & PhNCS \\
\hline \multicolumn{7}{|c|}{ Индексы удерживания $\mathrm{I}_{\mathrm{r}}$} \\
\hline 1351 & 1439 & 1824 & 784 & 872 & 1257 \\
\hline
\end{tabular}

В соответствии с инкрементами функциональных групп [12] наибольший вклад в индексы удерживания соединений вносят фрагменты $\mathrm{C}=\mathrm{S}$ (соответствующий инкремент составляет 480), фрагменты N-H (суммарный инкремент 396) и бензольное кольцо (инкремент 684). Столь высокий вклад полярных функциональных групп $\mathrm{N}-\mathrm{H}$ может быть связан с тем, что они понижают летучесть исследуемых соединений, способствуют образованию димеров и ассоциатов в газовой фазе, а также с их взаимодействием с атомом кислорода в полидиметилсилоксане. В то же время пло- 
ская геометрическая форма молекул II, III не оказывает такого большого влияния, как в случае углеродных сорбентов, поэтому разница в удерживании этильных и аллильных производных невелика.

Для сравнения в табл. 3 приведены значения индексов удерживания тиосемикарбазидов и изотиоцианатов на более полярной капиллярной колонке на основе полиэтиленгликоля. Их значения выше в 1.5-2 раза, чем на колонке с полидиметилсилоксаном, что несколько увеличит время хроматографического анализа. Таким образом, теоретически обоснована возможность достаточно хорошего разделения смеси тиосемикарбазидов и исходных изотиоцианатов, используемых с избытком в реакциях дериватизации.

Таблица 3. Индексы удерживания $\mathrm{I}_{\mathrm{r}}$ 1,1-диметилтиосемикарбазидов (I-III) и изотиоцианатов RCNS на полиэтиленгликолевой неподвижной фазе

\begin{tabular}{|c|c|c|c|c|c|}
\hline \multicolumn{5}{|c|}{ Вещество } \\
\hline I & II & III & EtNCS & AllNCS & PhNCS \\
\hline \multicolumn{7}{|c|}{ Индексы удерживания I $\mathrm{r}_{\mathrm{r}}$} \\
\hline 2473 & 2618 & 3131 & 1196 & 1341 & 1854 \\
\hline
\end{tabular}

На рис. 2 приведена экспериментальная хроматограмма реакционной смеси этил- и аллилизотиоцианатов (пики 1 и 2, соответственно) с этил- и аллилтиосемикарбазидами I и II (пики 3 и 4, соответственно). А на рис. 3 представлены масс-спектры исследованных тиосемикарбазидов. В масс-спектре I присутствуют интенсивный пик молекулярного иона с $m / z=147$ и пики характеристических ионов с $m / z=59$ и 60 , обусловленных, предположительно, элиминированием иона ДГ с $m / z=60$ и его фрагмента с $m / z=59$. В масс-спектре II присутствует пик молекулярного иона с $m / z=159$ и пики характеристических ионов с $m / z=115$ и 116 , образование которых можно объяснить внутримолекулярной циклизацией вещества [5].

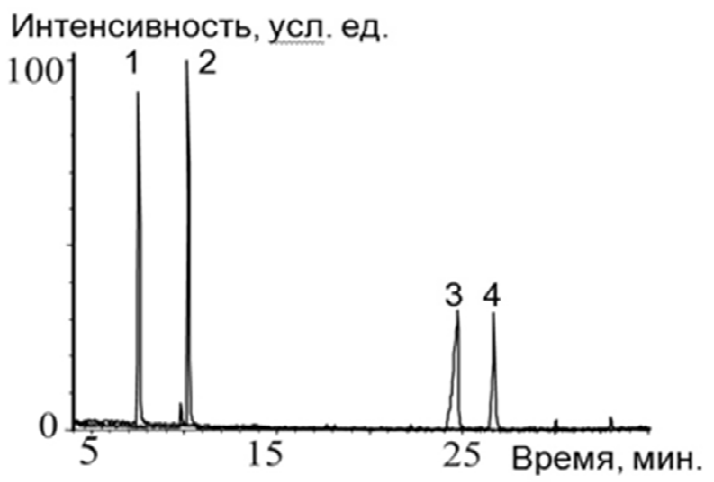

Рис. 2. Хроматограммы реакционных смесей этил- и аллилизотиоцианатов

( 1 и 2, соответственно) с этил- и аллилтиосемикарбазидами I и II

(3 и 4 , соответственно)

Как видно на рис. 2, смеси тиосемикарбазидов I и II удается разделить между собой и легко отделить от изотиоцианатов в предлагаемых хроматографических условиях. Как и предсказано теоретически, тиосемикарбазид I выходит несколько раньше, чем II. Алкильный заместитель обеспечивает более высокую летучесть этилтиосемикарбазида, по сравнению с аллильным аналогом. Температуры кипения этих соединений - 226 и $243^{\circ} \mathrm{C}$, соответственно [13]. Соединение III, кипящее при $319^{\circ} \mathrm{C}$, полностью разложилось в хроматографической системе на диметилгидразин и фенилизотиоцианат. Таким образом, метод газовой хроматографии с полидиме- 
тилсилоксановым сорбентом можно с успехом использовать для разделения соединений I и II и их отделения от избытка исходных реагентов. Это улучшает количественное определение ДГ благодаря повышенной точности измерения площади хроматографического пика его производного, не перекрывающегося с хроматографическим пиком дериватизатора. Дериват III, вероятно, можно будет отделить от других исследуемых соединений и реагентов с использованием парофазного ввода пробы.

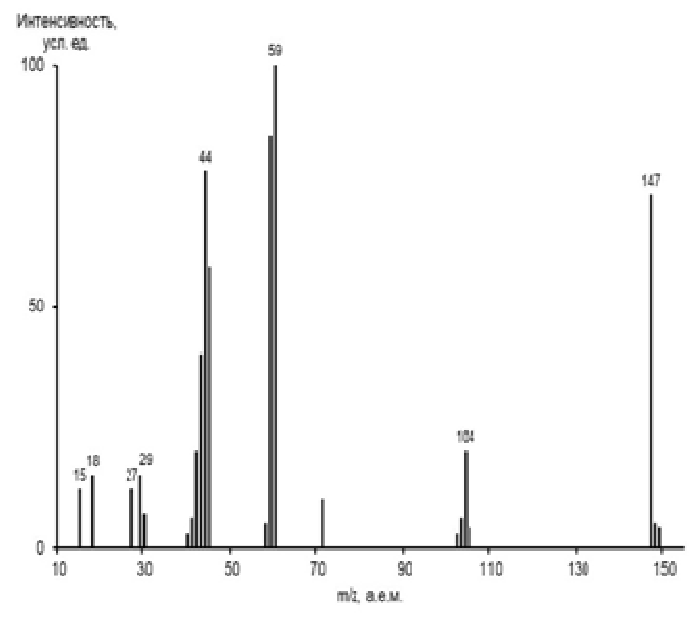

I

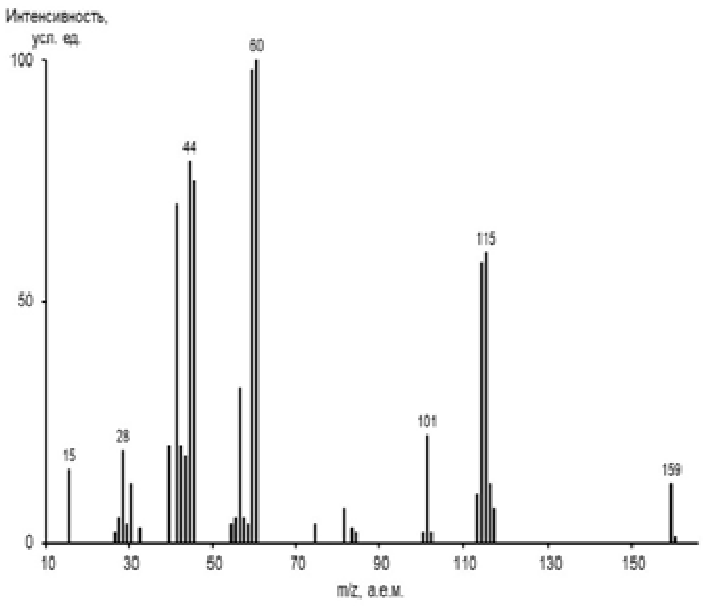

II

Рис. 3. Масс-спектры ЭИ 4-этил-1,1-диметилтиосемикарбазида (I) и 4-аллил-1,1-диметилтиосемикарбазида (II)

На рис. 4 приведена зависимость между экспериментально измеренными $\left(t_{\mathrm{R}}\right)$ и теоретически рассчитанными $\left(I_{\mathrm{r}}\right)$ характеристиками удерживания дериватов ДГ и изотиоцианатов (в соответствии с данными табл. 2). Линейная зависимость между экспериментальными и расчетными данными может быть описана уравнением $y=32.114 x+561.55$ с высоким коэффициентом корреляции $r^{2}=0.9967$.

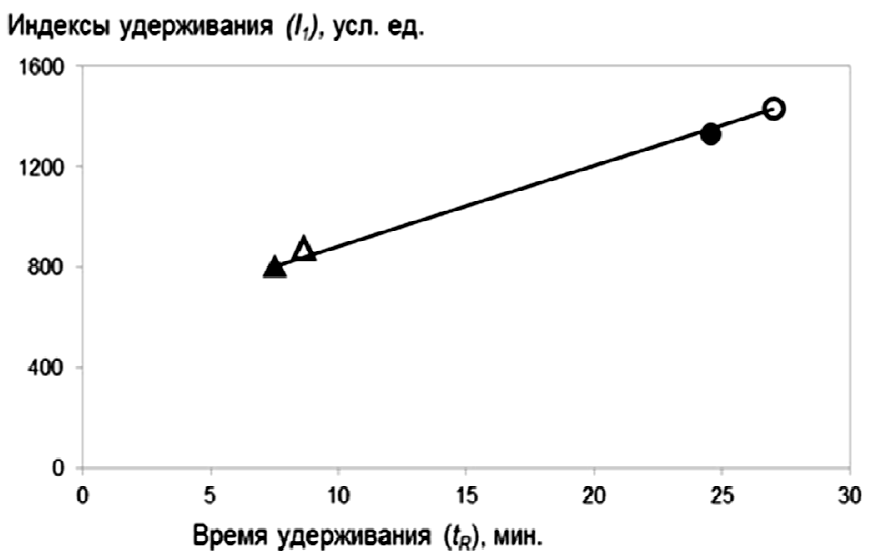

Рис. 4. Корреляционная зависимость времени хроматографического удерживания на колонке DB-5 и теоретически рассчитанных индексов удерживания этили аллилизотиоцианатов (треугольники) и этил- и аллилтиосемикарбазидов (кружки)

Таким образом, использование изотиоцианатов в качестве дериватизирующих реагентов для 1,1-диметилгидразина позволяет проводить дериватизацию без катализатора в мягких условиях и обеспечивает эффективность хроматографического разделения пары изотиоцианат - 1,1-диметилтиосемикарбазид. Повышение надежности масс-спектрометрической идентификации 1,1-диметилгидразина достигается 
применением этил- или аллилизотиоцианата в качестве дериватизирующего реагента, имеющего характерную фрагментацию при ионизации электронами.

\section{Заключение}

Проведены теоретические и экспериментальные исследования возможности хроматографического разделения смеси реагентов и продуктов реакции дериватизации 1,1-диметилгидразина с помощью изотиоцианатов. Методом газовой хроматографии на полидиметилсилоксановой неподвижной фазе эффективно разделены смеси этил- и аллилтиосемикарбазидов с дериватизирующими реагентами. Получена удовлетворительная корреляция между экспериментальными и теоретически рассчитанными характеристиками удерживания тиосемикарбазидов и изотиоцианатов на неполярной неподвижной фазе.

Работа выполнена в рамках Государственного задания ИФХЭ РАН и при частичной финансовой поддержке РФФИ (проект № 18-08-01224).

Acknowledgments: The work supported by the RFBR 18-08-01224a

\section{Список литературы}

1. Schmidt W.E. Hydrazine and its derivatives. 2nd Ed. New York. Wiley. 2001. 2121 p.

2. Holtzclaw J.R., Rose S.L., Wyatt J.R. // Anal. Chem. 1984. Vol. 56. pp. 2952-2956.

3. Smolenkov A.D., Shpigun O.K. // Talanta. 2012. Vol. 102. pp. 93-99.

4. Blau K., Halket J.M. Handbook of Derivatives for Chromatography. Chichester. Wiley. $1993.370 \mathrm{p}$.

5. Савельев Ю.В., Храновский В.А., Веселов В.Я., Греков А.П. и др. // Журнал органической химии. 2003. Т. 39. С. 105-108.

6. Парамонов С.А., Ульянов А.В., Буряк А.К. // Известия АН. Сер. хим. 2010. Т. 59. С. 25-30.

7. Лебедев А.Т. Масс-спектрометрия в органической химии. М. БИНОМ. 2003. 493 c.

\section{References}

1. Schmidt W.E., Hydrazine and its derivatives, 2nd Ed. New York, Wiley, 2001. 2121 p.

2. Holtzclaw J.R., Rose S.L., Wyatt J.R.,/ Anal. Chem., 1984, Vol. 56, pp. 2952-2956.

3. Smolenkov A.D., Shpigun O.K., Talanta, 2012, Vol. 102, pp. 93-99.

4. Blau K., Halket J.M., Handbook of Derivatives for Chromatography, Chichester, Wiley, 1993. $370 \mathrm{p}$.

5. Savel'ev Ju.V., Hranovskij V.A., Veselov V.Ja., Grekov A.P. et al., Zhurnal Organicheskoj Khimii, 2003, Vol.39, pp. 105-108.
8. Буряк А.К. // Успехи химии. 2002. Т. 71. C.788-790.

9. Матюшин Д.Д., Буряк А.К. // Сорбизионные и хроматографические прочессы. 2017. T. 17.№ 2. C. 204-211.

10. Матюшин Д.Д., Уклеина А.Н., Буряк А.К. // Сорбиионные и хроматографические прочессы. 2017. Т. 17. № 6. С. 935-942.

11. Краткий справочник физикохимических величин / Под ред. А.А. Равделя, А.М. Пономаревой. СПб.: Специальная литература, 1998. 298 с.

12. Stein S.E., Babushok V.I., Brown R.L., Linstrom P.J. // J. Chem. Information and Modeling. 2007. Vol. 47. pp. 975-980.

13. Stein S.E., Brown R.L. // J. Chem. Information and Modeling. 1994. Vol.34. pp. 581587.

6. Paramonov S.A., Ul'janov A.V., Burjak A.K., Izvestija AN. Ser. him., 2010, Vol. 59, pp. 25-30.

7. Lebedev A.T., Mass-spectrometriya $\mathrm{v}$ organicheskoi chimii, M., BINOM, 2003. 493 p.

8. Burjak A.K., Uspehi khimii, 2002, Vol. 71, pp.788-790.

9. Matjushin D.D., Burjak A.K., Sorbtsionnye ik hromatograficheskie protsessy, 2017, Vol. 17, No 2, pp. 204-211. 
10.Matjushin D.D., Ukleina A.N., Burjak A.K., Sorbtsionnye $i$ khromatograficheskie protsessy, 2017, Vol. 17, No 10. pp. 935-942.

11.Kratkij spravochnik fiziko-himicheskih velichin, Ed. A.A. Ravdel, A.M. Ponomareva. SPb., Special'naja literature, 1998. 298 p.

Ульянов Алексей В. - к.Х.Н, ИФХЭ РАН, Москва, (495) 955-46-85

Полунина Ирина Александровна - к.Х.н, доцент, ИФХЭ РАН, Москва, (495) 955-46-90

Полунин Константин Евгеньевич - к.х.н, доцент, ИФХЭ РАН, Москва, (495) 955-46-90

Буряк Алексей Константинович - д.Х.н, профессор, ИФХЭ РАН, Москва, (495) 955-46-85
12.Stein S.E., Babushok V.I., Brown R.L., Linstrom P.J., J. Chem. Information and Modeling, 2007, Vol. 47, pp. 975-980.

13.Stein S.E., Brown R.L., J. Chem. Information and Modeling., 1994, Vol.34, pp. 581-587.

Ulyanov Aleksey V. - Ph.D. (chemistry), IPCE RAS, Moscow

Polunina Irina A. - Ph.D. (chemistry), associate prof., IPCE RAS, Moscow, ipcepol@gmail.ru

Polunin Konstantin E - Ph.D. (chemistry) associate prof., IPCE RAS, Moscow, polunira@mail.ru

Buryak Alexei K. - prof., Dr.Sci. (chemistry), IPCE RAS, Moscow, akburyak@mail.ru 